\title{
$\infty \sqrt{1}$ Stroke and \\ Cerebral aneurysm treatment: modern neurovascular techniques
}

\author{
Bowen Jiang, ${ }^{1}$ Michelle Paff, ${ }^{2}$ Geoffrey P Colby, ${ }^{1}$ Alexander L Coon, ${ }^{1}$ Li-Mei Lin ${ }^{2}$
}

To cite: Jiang B, Paff M, Colby GP, et al. Cerebral aneurysm treatment: modern neurovascular techniques. Stroke and Vascular Neurology 2016;1: e000027. doi:10.1136/svn2016-000027

Received 19 June 2016 Revised 26 July 2016 Accepted 28 July 2016 Published Online First 17 August 2016

CrossMark

\section{${ }^{1}$ Department of Neurosurgery, Johns Hopkins University School of Medicine, The Johns Hopkins Hospital, Baltimore, \\ Maryland, USA \\ ${ }^{2}$ Department of \\ Neurosurgery, University of California, Irvine School of Medicine, UC Irvine Medical Center, Orange, California, USA}

Correspondence to Dr Li-Mei Lin;

limei.lin@uci.edu

\section{ABSTRACT}

Endovascular treatment of cerebral aneurysm continues to evolve with the development of new technologies. This review provides an overview of the recent major innovations in the neurointerventional space in recent years.

\section{HISTORY OF ENDOVASCULAR TREATMENT}

The neurosurgical treatment of intracranial aneurysms dates back to 1937, when Dandy ${ }^{1}$ described microsurgical obliteration of a posterior communicating artery aneurysm. For decades, microsurgical clipping remained the gold standard and foremost modality for treatment of cerebral aneurysms. Endovascular therapies emerged in the 1990s with the advent of the Guglielmi detachable coil system. This system established neurointervention as a new field, with multiple randomised clinical trials demonstrating the efficacy and safety of coil embolisation. ${ }^{2}{ }^{3}$ Despite these early favourable results, postcoiling aneurysm recanalisation remained a challenge in the field. For instance, Raymond et al $\mathrm{s}^{4}$ experience with 501 cerebral aneurysms treated with endovascular coiling demonstrated that complete angiographic occlusion rate was approximately only $38 \%$ at 1 -year follow-up. The data were further corroborated by Gory and Turjman, ${ }^{5}$ whose prospective, multicentre European study of 404 aneurysms treated with Nexus detachable coils (ev3-Covidien, Irvine, California, USA), showed $22 \%$ neck remnant and $30 \%$ aneurysmal remnant, with a $17.7 \%$ recanalisation rate and $21.6 \%$ thrombosis rate at 13 months angiographic follow-up.

To address these shortcomings, the neuroendovascular space quickly experienced significant technological advancements aimed at improving the different properties of a coil, including coil lengths, shapes, softness and detachment zones. These developments have translated to improvements in clinical outcomes of cerebral aneurysms treated with coiling. For example, HydroCoils (MicroVention, Tustin, California, USA) have allowed for treatment of more complex aneurysmal configurations with a reduction in recurrence rates compared with bare-platinum coils. ${ }^{6} 7$ Additionally, new neuroendovascular devices such as intracranial stents and balloons were developed to augment coil embolisation. In balloonassisted coil embolisation, typically a compliant balloon is positioned across the neck of the aneurysm to provide a scaffold protecting the parent artery while coils are deployed through a microcatheter into the aneurysm sac. This reduces the risk of coil prolapse into the parent vessel and can also provide immediate protection in an event of intraprocedural aneurysm rupture during the coiling due to the ability to achieve endovascular proximal control with balloon inflation. Comparatively, stent-assisted coil embolisation was developed to improve the occlusion rate and coil packing density of wide-necked as well as large and giant aneurysms. During this process, the stent (similar to a balloon) is positioned across the aneurysm neck, providing a scaffold to protect the parent artery. This minimises coil loop prolapse and allows for higher density coil packing, leading to a reduction in recurrence rates and higher rates of angiographic occlusion. ${ }^{8-10}$

Despite these technological advancements in coil embolisation, aneurysms with large diameters $(>10 \mathrm{~mm})$, wide necks, unfavourable dome-to-neck ratios $(<2)$ and fusiform configuration remain therapeutic challenges and dilemmas, with as high as $>20 \%$ poor outcome (aneurysm recurrence or treatment-related morbidity/mortality) associated with the management of large/giant aneurysms. ${ }^{11}{ }^{12}$ To meet these challenges, device innovations have ushered in new therapeutic concepts, including flow diversion and intrasaccular flow disruption.

\section{FLOW DIVERSION REVOLUTION}

The concept of flow diversion serendipitously stemmed from the lessons garnered from stent-assisted coil embolisation. When research studies demonstrated that denser 
coil packing with less coil prolapse into the parent vessel correlated with improved clinical and radiographic outcomes, fluid dynamic analysis revealed that endovascular stents actually accelerated aneurysmal thrombosis and alteration in blood flow into the aneurysm from the parent vessel. ${ }^{9} 13 \quad 14$ Flow diversion is fundamentally based on two concepts illustrated in figure 1: (1) the placement of a high-mesh density stent in the parent vessel disrupts blood flow into the aneurysm and (2) the stent provides a scaffold for which endothelium can grow, subsequently isolating the aneurysm from the parent circulation. ${ }^{15}$ Flow diversion thus allows for progressive intra-aneurysmal thrombosis over time with subsequent radiographic obliteration of the aneurysm. The advantage of endoluminal flow diversion over endosaccular coiling is the ability to treat the weakened abnormal arterial wall by providing a scaffold for neoendothelialisation to occur. This neoendothelialisation process results in a durable occlusion of the aneurysm that often provides a curative outcome as compared with the known recurrence associated with coiling. Figure 2 demonstrates a case example of a large left-sided cavernous internal carotid artery (ICA) aneurysm that was treated with a flow diverter deployed within the parent ICA and evidence of complete aneurysm occlusion on the 6-month follow-up angiography. Additionally, with the endoluminal approach, the aneurysm sac does not need to be accessed during the treatment, which subsequently eliminates the risk of intraprocedural aneurysm rupture inherent with endosaccular coiling.
The first introduction of flow diversion into the neuroendovascular space was in 2007, with the invention of the Pipeline Embolization Device (PED; Medtronic Neurovascular, Irvine, California, USA) ${ }^{16}$ Since then, a plethora of flow diverters have entered the neurointerventional field including the Silk flow diverter (Balt Extrusion, Montmorency, France), Flow-Redirection Endoluminal Device (FRED; MicroVention, Tustin, California, USA), Surpass (Stryker Neurovascular, Freemont, California, USA), Tubridge (MicroPort Medical, Shanghai, China) and p64 Flow Modulation Device (Phenox, Bochum, Germany). Most of these flow diverters are commercially available in Europe and South America. In the USA, however, PED is the only available flow diverter after its approval by the Food and Drug Administration (FDA) in 2011. ${ }^{17}$

\section{Pipeline Embolization Device}

The PED is a braided mesh designed with 48 strands consisting of $25 \%$ platinum-tungsten and $75 \%$ cobaltchromium-nickel alloy. When fully deployed, the PED provides $35 \%$ metallic surface-area coverage with pore size of $0.02-0.05 \mathrm{~mm}^{2}$ at nominal vessel diameter. ${ }^{15}$ The PED is available in sizes ranging from 2.5 to $5.0 \mathrm{~mm}$ in diameter (in $0.25 \mathrm{~mm}$ increments) and $10-35 \mathrm{~mm}$ in length (in $2 \mathrm{~mm}$ increments from 10 to $20 \mathrm{~mm}$, and $5 \mathrm{~mm}$ increments from 20 to $35 \mathrm{~mm}$ ). The PED delivery system comes attached to a $0.016^{\prime \prime}$ diameter stainless steel delivery wire, with the segment where it is mounted

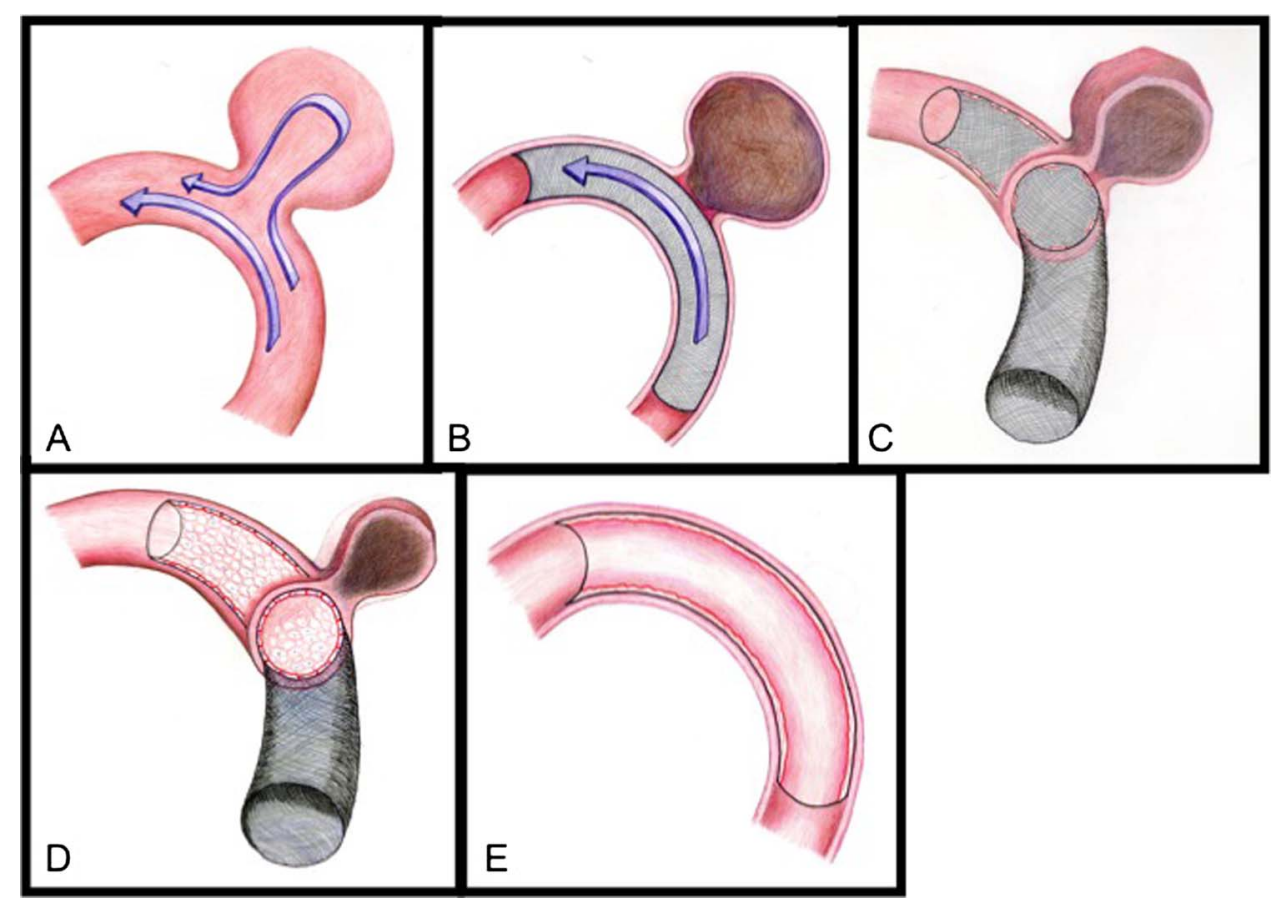

Figure 1 Flow diversion concept: placement of a high-mesh density stent (flow diverter) in the parent vessel disrupts blood flow into the aneurysm (A and $B$ ), allowing for progressive intra-aneurysmal thrombosis over time with subsequent obliteration of the aneurysm ( $C$ and $D)$. Additionally, the flow diverter provides a scaffold for neoendothelialisation, which treats the weakened abnormal arterial wall and isolates the aneurysm from the parent circulation resulting in durable occlusion of the aneurysm (E). 


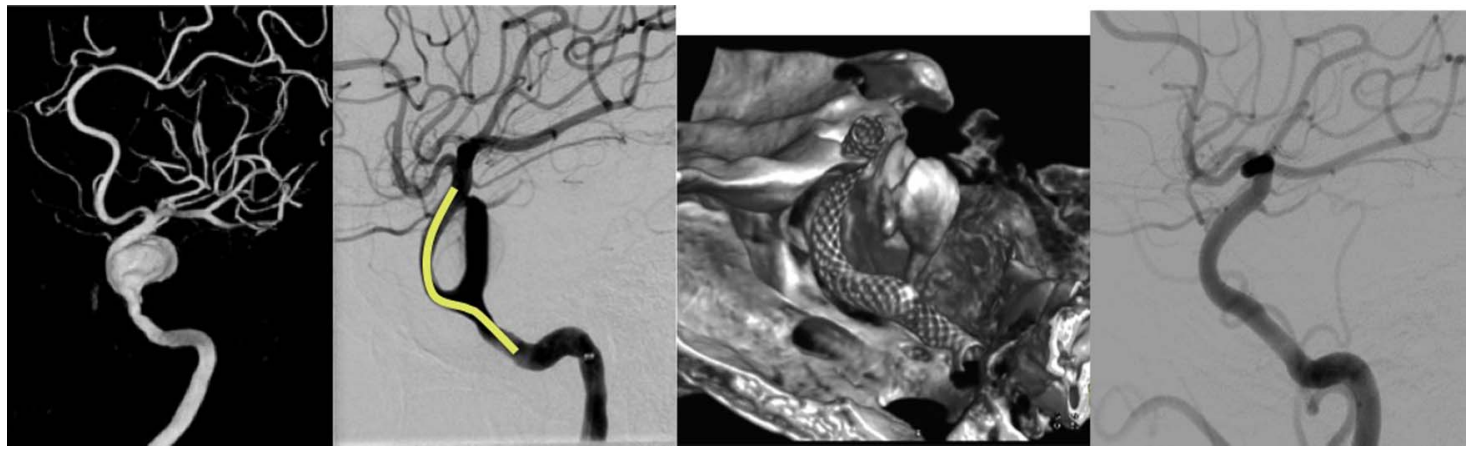

Figure 2 Flow diversion treatment of a large left cavernous aneurysm with complete occlusion of the aneurysm demonstrated at 6-month follow-up angiogram.

being $0.008^{\prime \prime}$ thick. It is delivered via a $0.027^{\prime \prime}$ delivery microcatheter, such as the Marksman (Medtronic Neurovascular, Irvine, California, USA) or a similar size microcatheter. The second-generation PED, named Pipeline Flex (PED Flex), received the European CE mark of approval in March 2014 and subsequently received FDA approval in February 2015. Its design includes numerous delivery system changes to enhance device opening and provide additional safety with a resheathing feature. ${ }^{18}$ The PED's on-label usage as dictated by the FDA is limited to the treatment of large or giant $(\geq 10 \mathrm{~mm})$ wide-necked intracranial aneurysms from the petrous to the superior hypophyseal segments of the ICA. ${ }^{17}$

Clinical experience worldwide with PED has demonstrated the effectiveness, durability, safety and cost-effectiveness of endovascular endoluminal reconstruction primarily in large and giant aneurysms. Initial reports from Buenos Aires and Budapest series demonstrated complete radiographic occlusion rates in the 90-93\% range at 6 months follow-up angiogram. ${ }^{19} 20$ These studies paved the way to the PED for the Intracranial Treatment of Aneurysms Trial (PITA), which showed $93.3 \%$ angiographic occlusion rates at 6 months (28 of 30 aneurysms), with $6.5 \%$ of patients having major stroke or neurological complication (2 of 31 patients). ${ }^{16}$ Similarly, the PED for Uncoilable or Failed Aneurysms (PUFs) multicentre clinical trial that led to the FDA premarket approval of the PED in 2011, demonstrated in 108 patients across 10 prospective centres high rates of primary efficacy $(81.8 \%$ of aneurysm with complete occlusion at 6 months) with low complication rate $(5.6 \%$ of patients with major strokes or neurological injury at 180 days). ${ }^{21}$ Taken together, all of the trials demonstrated relatively high rates of aneurysm occlusion (81.8$93.3 \%$ ) with low rates of major morbidity and mortality $(0-6.5 \%) .^{16} 19-21$

Other subsequent studies for the on-label usage of PED have corroborated the trial data at the institutional level, with similar rates of radiographic success with low rates of postprocedural morbidity and mortality. ${ }^{22}$ Studies have further demonstrated the cost-effectiveness of using PED as advantageous over traditional stent-assisted coiling of large anterior circulation aneurysms $(27.1 \%$ cost reduction per millimetre of aneurysm treated in the PED group compared with stent-assisted coiling). ${ }^{23}$ Treatment of large and giant proximal ICA aneurysms using PED also requires less radiation, less fluoroscopy time and less contrast administration than standard coiling techniques, with an average radiation dose of $2840 \mathrm{mGy}$ with PED treatment compared with 4010 mGy with traditional coiling techniques. ${ }^{24}$

Although PED is FDA approved for large and giant intracranial aneurysms, these aneurysms only encompass a small fraction of all intracranial aneurysms. In contrast, over $80 \%$ of all cerebral aneurysms found in the general population are $<10 \mathrm{~mm}$ in size. ${ }^{25} 26$ There is considerable documentation in the literature that the majority of ruptured aneurysms are smaller than $10 \mathrm{~mm} .{ }^{27}$ Treatment of small aneurysms $(<10 \mathrm{~mm})$ with flow diverters may be advantageous over traditional endosaccular modalities. Lin and colleagues retrospectively reviewed a prospective, single-centre aneurysm database to identify 41 patients with 44 PED cases. In this series, mortality was reported in $2.3 \%$ while by 6 months post-PED implantation, angiographic success was observed in $80 \% .^{28}$ This experience with PED treatment for small ICA aneurysms is comparable to the few published reports on this experience, with mortality range of $0 \%$ observed by Chan et al, ${ }^{29}$ and $11 \%$ observed by Lubicz et $a l l^{30}$ which is comparable with the PED experience for large and giant aneurysms with reported mortality rates up to $5.5 \%$.

A wealth of experience has been garnered in the neuroendovascular space with the PED since its introduction, such that treatment of large and giant ICA aneurysms with flow diversion is now a widely accepted standard approach. As a result of the success with PED treatment of these complex aneurysms, there is also an expansion of interest and data supporting the safety as well as efficacy of PED treatment in an 'off-label' manner with small anterior circulation aneurysms as well as select posterior circulation aneurysms. ${ }^{31-33}$

\section{Surpass flow diverter}

The Surpass flow diverter is similar to the PED in design consisting of a braided mesh constructed of cobalt- 
chromium alloy intertwined with platinum-tungsten wires for visibility. Compared with PED, the Surpass has a lower porosity and is designed to maintain constant pore density over various diameters of the device. Additionally, the Surpass flow diverter exists in fewer sizes with only 3,4 and $5 \mathrm{~mm}$ diameter options. The 3 and $4 \mathrm{~mm}$ devices have 72 wires, and the $5 \mathrm{~mm}$ device has 96 wires. Unlike the PED, the Surpass device is preloaded at the distal end of a microcatheter delivery system that consists of a $0.040^{\prime \prime}$ inner diameter (ID) delivery micocatheter and pusher. The entire Surpass delivery system is advanced over a $0.014^{\prime \prime}$ microwire inserted through the pusher. The implant is deployed by a combination of advancing the pusher and unsheathing the microcatheter. ${ }^{34}$

Wakhloo et $a l^{35}$ reported the largest study on safety and efficacy of Surpass, with a prospective, multicentre, non-randomised, single-arm design of 165 patients with 190 intracranial aneurysms of the anterior and posterior circulations enrolled from 24 centres. Successful deployment of the Surpass flow diverter was observed in $98 \%$ of the aneurysms. Follow-up angiography available in $158(86.8 \%)$ intracranial aneurysms showed $100 \%$ occlusion in $75 \%$ of the cases at radiographic follow-ups. Permanent neurological morbidity and mortality were $6 \%$ and $2.7 \%$, respectively. Morbidity occurred in $4 \%$ and $7.4 \%$ of patients treated for aneurysms of the anterior and posterior circulation, respectively. These data demonstrate that the clinical safety profile is similar to that of stent-assisted coil embolisation and PED treatment with high rates of radiographic occlusion. ${ }^{35}$

Colby and colleagues reported the initial North American experience with Surpass. In this study, 20 patients with ICA aneurysms $\geq 10 \mathrm{~mm}$ with $\geq 4 \mathrm{~mm}$ neck were treated as part of the Surpass IntraCranial Aneurysm Embolization System Pivotal Trial (the SCENT trial; Stryker). ${ }^{36}$ The Surpass device was implanted in $19 / 20(95 \%)$ cases. Of 19 cases, a single device was used in 18 cases $(95 \%)$ and two devices in only 1 case $(5 \%)$. Balloon angioplasty was performed in $8 / 19$ cases (42\%). Complete aneurysm neck coverage and adequate vessel wall apposition was obtained in all 19 cases without acute morbidity or mortality. An advantage of Surpass flow diverter is the Surpass delivery system that allows for a torque-free, over-the-wire deployment of the device. ${ }^{36}$ Additionally, this system provides the safety of maintaining a continuous endoluminal wire access that is uncoupled from the device deployment.

\section{Other flow diverters}

Silk

The Silk is a self-expandable stent consisting of a tightly woven structure, supplied with a soft microcatheter and has resheathing and relocation abilities. For the majority of studies in the literature, Silk is used for large and giant neck fusiform aneurysms with a wide neck (dome-to-neck ratio of $<2 \mathrm{~mm}$ or neck $>4 \mathrm{~mm}$ ). Strauss and Maimon $^{37}$ retrospectively reviewed patient data from 2008 to 2013 and identified 60 patients with 67 aneurysms (15 posterior circulation, 52 anterior circulation). They concluded a 'good' angiographic result in $88 \%$ or $53 / 60$ aneurysms, with a good outcome defined as complete or near-complete angiographic occlusion at 15 months. The group identified aneurysm size as a positive predictor of complication rate $(0 \%$ in smaller aneurysms, $16.7 \%$ in large aneurysms and $42.9 \%$ in giant aneurysms). Giant aneurysms of the posterior circulation had unfavourable results, with $57 \%$ complication rate due to brainstem ischaemia secondary to perforator occlusion. ${ }^{37}$ These data are further corroborated by Lubicz et al, ${ }^{38}$ who reported a $11 \%$ delayed complication rate with overall neurological morbidity of $5.5 \%$; however, all complications were reported with the firstgeneration Silk device. In an eight-centre study in Canada by Shankar and colleagues, perioperative morbidity and mortality were $8.7 \%$ and $2.2 \%$, respectively. At the last available follow-up, $83.1 \%$ of the aneurysms were either completely or near completely occluded, with the rate of complications was higher for fusiform aneurysms $(\mathrm{p}<0.001) .^{39}$

Taken together, these data show a trend towards better outcomes for smaller and anterior circulation aneurysms and overall consistent radiographic outcomes for flow diversion of large and/or fusiform aneurysms with the Silk device.

\section{Flow-Redirection Endoluminal Device}

The FRED system is flow diverter with a compliant closed-cell paired stent (aka 'stent within a stent') composed of single wire braid self-expanding nickel titanium. Initial experience with this device remains limited. Diaz et $a t^{40}$ reviewed 13 patients with 14 treated aneurysms. Although no long-term angiographic data are available, there were no technical or immediate postprocedural complications. The authors concluded the device was technically easy to deploy and articulates the ability for the device to be recaptured after partial deployment and to maintain its internal shape in tortuous vessels as particular advantage. Long-term clinical and angiographic clinical studies are necessary to further study this device.

\section{p64}

The p64 Flow Modulation Device is a braided mesh tube composed of a 64 nickel-titanium nitinol alloy. The device is compatible with a $0.027^{\prime \prime}$ ID microcatheter. It is available in sizes $2.5-5 \mathrm{~mm}$ diameter with $12-36 \mathrm{~mm}$ length. There are limited clinical data on this flow diverter, with an initial experience and technical aspects reported by Briganti and colleagues. In their series of six intracranial aneurysms, immediate post-treatment angiography showed reduced flow into all aneurysms, although no long-term angiographic data are available. ${ }^{41}$ The authors reported no periprocedural technical complications and no early or delayed aneurysm rupture, no ischaemic or haemorrhagic complications, and no 
neurological morbidity or deaths. The authors note that the mechanical detachment feature, with $100 \%$ retrievability, is a potential advantage of this new device. ${ }^{41}$

\section{Tubridge flow diverter}

The Tubridge is a flow diverter developed by MicroPort Medical Company and is a braided, self-expanding stent-like device with flared ends. A large Tubridge (diameter $\geq 3.5 \mathrm{~mm}$ ) is braided with 62 nickel-titanium microfilaments and 2 platinum-iridium radiopaque microfilaments, whereas a smaller Tubridge (diameter $<3.5 \mathrm{~mm}$ ) is composed of 46 nitinol and 2 platinumiridium microfilaments. Initial experience from Zhou et $a t^{42}$ on 28 patients with large or giant ICA aneurysms showed a $0 \%$ morbidity and mortality rate periprocedurally. At a mean follow-up of 10 months, $72 \%$ of the aneurysms were completely occluded and $24 \%$ were improved, with $4 \%$ showing no significant change. ${ }^{42}$ After approval from the Chinese FDA, the device is currently being studied in a multicentre, randomised, controlled clinical trial. ${ }^{43}$ In this study, Zhou et al will enrol 124 patients and randomise into a treatment group consisting of Tubridge or Tubridge with coils versus a control group treated with stent-assisted coiling.

\section{INTRASACCULAR FLOW DISRUPTION AND THE WOVEN ENDOBRIDGE DEVICE}

Flow diversion has proven promising to overcome limitations of traditional endovascular coiling techniques for the treatment of sidewall aneurysms; however, the management of large bifurcation aneurysms remains a challenge. For these bifurcation aneurysms, coiling with adjunctive devices such as temporary balloon protection or stent assistance are associated with increased procedural complexity, which lead to a higher chance of complications. Additionally, use of stents requires periprocedural dual-antiplatelet therapy with inherent risks of haemorrhage. In this context, a new device was developed to provide an innovative alternative strategy via intrasaccular flow disruption called the Woven EndoBridge (WEB; Sequent Medical, Aliso Viejo, California, USA). The WEB is a self-expanding, oblate, braided mesh of nitinol wires that is deployed into the aneurysm sac itself (figure 3). The initial WEB device consisted of a dual layer (WEB DL) design of inner and outer braids; however, this has since evolved to a single layer (WEB SL) device with a higher number of nitinol wires providing similar flow disruption effects. ${ }^{44}$ Prior to detachment of the WEB device, it can be fully retrieved. Additional modifications of the WEB SL device include a spherical shape (WEB SLS) and enhanced visualisation (WEB EV) provided by platinum-cored nitinol wires. Once a WEB device is deployed within the aneurysm sac, the WEB modifies the blood flow at the aneurysm neck, which induces thrombosis within the aneurysm. Figure 4 demonstrates two case examples of middle cerebral artery (MCA) bifurcation aneurysms treated with the WEB device.

Several retrospective institutional studies in Europe have demonstrated the initial safety and efficacy of the WEB device. ${ }^{44-47}$ Given the promising data, two prospective, good clinical practice series were conducted in Europe: WEBCAST and French Observatory. These single-arm, prospective, multicentre studies included ruptured and unruptured bifurcation

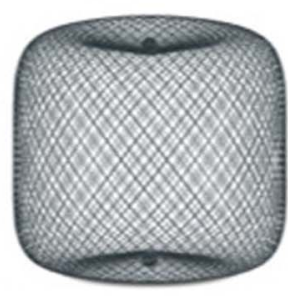

WEB-SL (Single Layer)

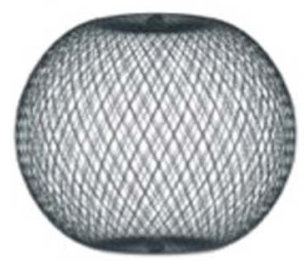

WEB SLS (Single Layer Spherical)

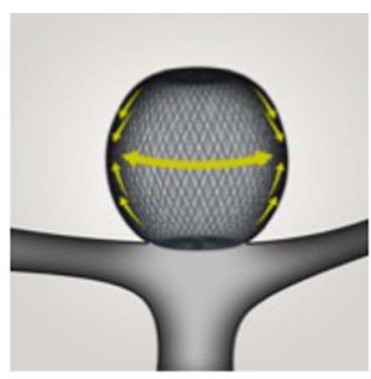

Radial compression holds WEB in aneurysm sac while conforming to aneurysm wall and sealing the neck

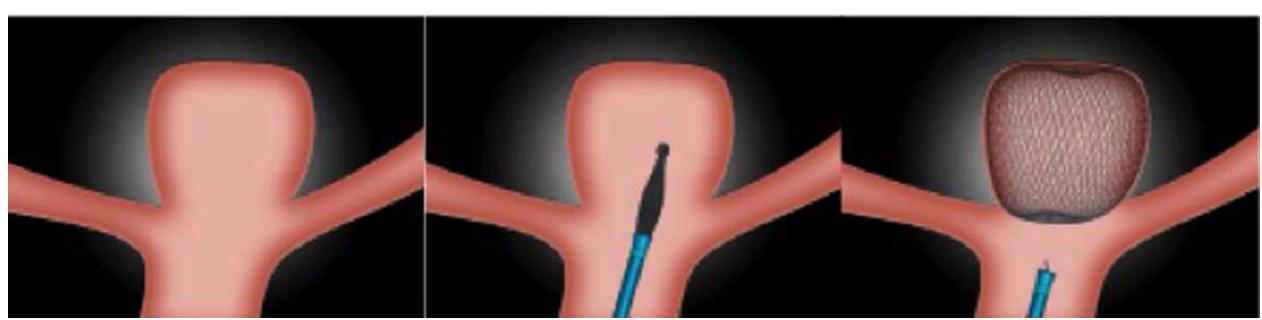

Figure 3 WEB intrasaccular flow disruption system. SL, single layer; WEB, Woven EndoBridge; WEB SLS, WEB SL device with a spherical shape. Images provided by Sequent Medical. 


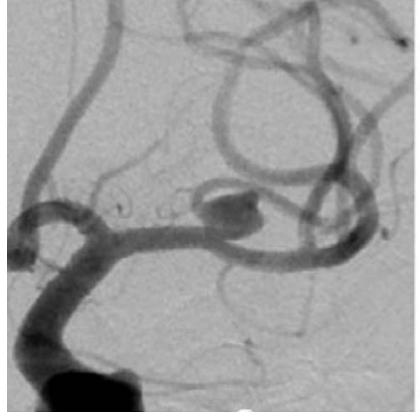

Pre

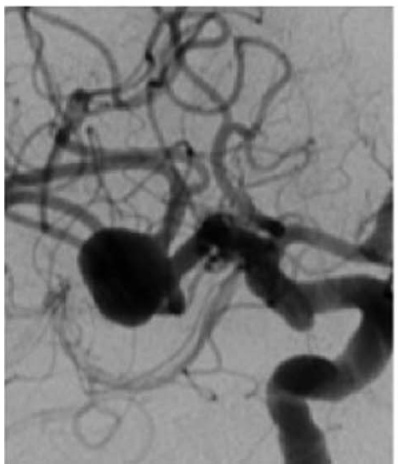

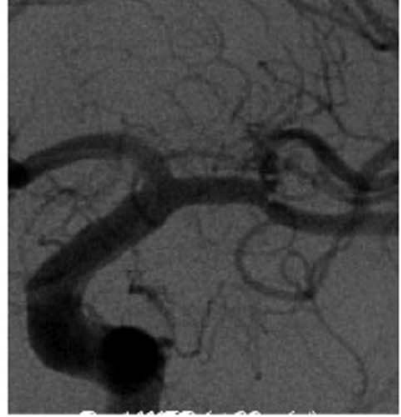

Post-WEB $(\leq 30$

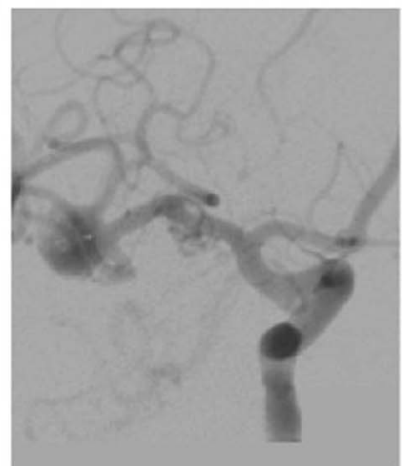

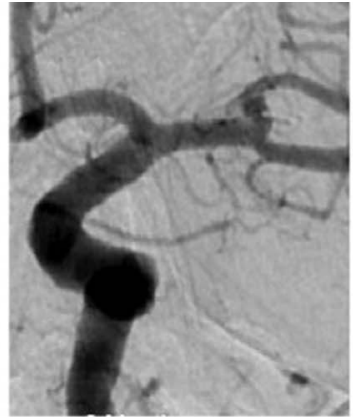

Follow-up 3-6

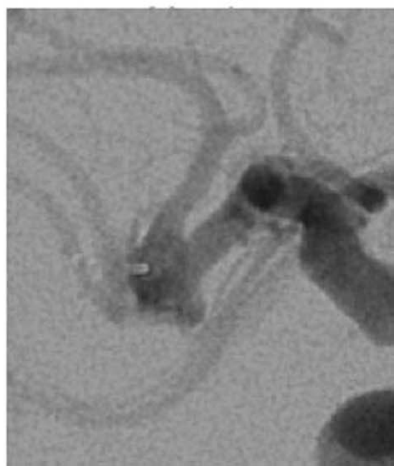

Figure 4 WEB treatment of MCA bifurcation aneurysms. Top row is a small left MCA bifurcation aneurysm. Bottom row is a large right MCA bifurcation aneurysm. WEB, Woven EndoBridge. Images provided by Sequent Medical.

aneurysms located in the basilar artery, middle cerebral artery, anterior communicating artery and ICA terminus. ${ }^{48}$ Postoperative, 6-month (in WEBCAST) and 1-year aneurysm occlusion was independently evaluated with a three-grade scale: complete occlusion, neck remnant and aneurysm remnant. A total of 113 patients with 114 aneurysms were treated. There was no mortality at 1 month, and morbidity was $2.7 \%$. At 1 year, complete aneurysm occlusion was observed in $56.0 \%$, neck remnant in $26.0 \%$ and aneurysm remnant in $18.0 \%$. Worsening of aneurysm occlusion between the procedure and 12 months was observed in $2.0 \%$ and between 6 months and 1 year in $7.1 \%{ }^{48}$

The combination of these two prospective studies represents the largest series of WEB cases in the literature. The advantage of the WEB device is the combination of an endosaccular approach with flow diversion. This eliminates the need for dual antiplatelet therapy required for endoluminal devices and subsequently allows use in the ruptured aneurysm setting with subarachnoid haemorrhages. Although the data are encouraging, the availability of the WEB device is still limited primarily to Europe and South America. In the USA, the multicentre clinical trial for premarket approval of the WEB completed enrolment in November 2015 and the data from the trial are still being collected.

\section{NEUROENDOVASCULAR CATHETER ACCESS SYSTEMI}

As neurointervention evolves with innovative devices such as flow diverters and intrasaccular devices, catheter access systems have also become more sophisticated. Fundamental to any neurointervention is the need for a stable catheter access and delivery system that offers varying degrees of trackability, distal and proximal support, and precise distal targeting. In essence, increased guide catheter support is required for procedures with larger device delivery systems, tortuous anatomy and distal targets.

Classically, neurointerventions were performed using a biaxial system consisting of a relatively rigid guide catheter (eg, Envoy) positioned in the cervical ICA and a small flexible microcatheter that was advanced intracranially to the target of interest. Often the microcatheter has to be advanced a considerable distance from the supporting guide catheter, thereby reducing the control and tactile feedback for the operator and increasing the propensity for unwanted slack in the system. These limitations are amplified in older patients with significant vessel tortuosity, and it can lead to technical failures that necessitate alternative more invasive approaches such as direct carotid puncture.

There has been a paradigm shift in the design and approach to catheter support systems for cases of flow diversion from a classic biaxial set-up with cervical positioning of guide catheters to a more robust triaxial system with intracranial positioning of intermediate support catheters. This is secondary to the comparatively larger size of the flow diverter delivery microcatheter (0.027" ID for the PED) and the significant intradeployment manipulations required for proper device implantation. The Navien (Medtronic Neurovascular, Irvine, 
Figure 5 Optimisation of WEB platform. WEB, Woven

EndoBridge. Images provided by Sequent Medical.

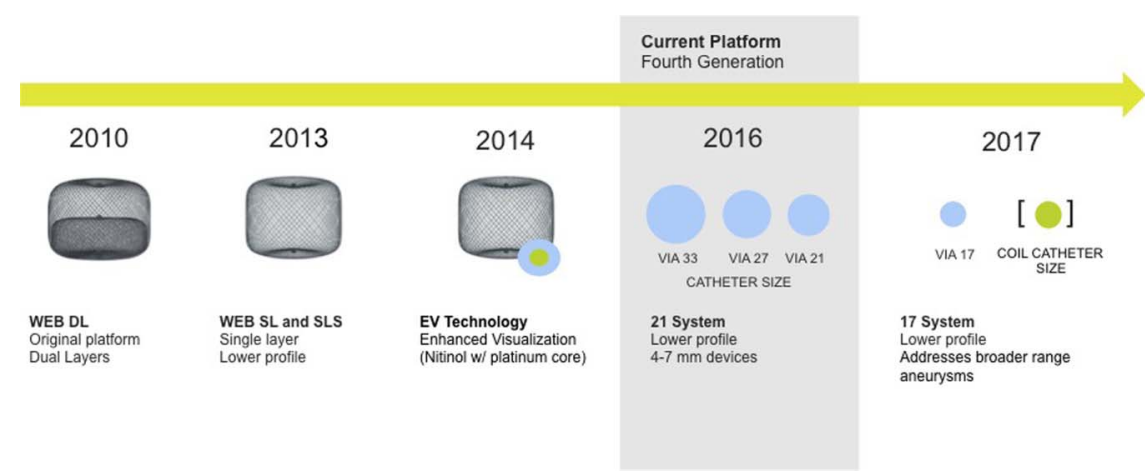

California, USA) is a newer generation 5 French $\left(0.058^{\prime \prime}\right.$ ID) distal intracranial catheter that is highly trackable and atraumatic with a large bore lumen that can accommodate 0.027 " ID delivery microcatheters used for flow diverters with added room for flush and contrast injections. There has been significant experience with the Navien for use in a variety of endovascular aneurysm treatments, including PED as well as stent-assisted coiling. These experiences demonstrate successful trackability of the catheter consistently to intracranial locations such as the ICA and MCA despite vessel tortuosity. ${ }^{49} 50$ The Navien catheter has also been instrumental when used as a salvage technique for cases where PED opening fails with standard deployment manoeuvres. ${ }^{51}$

This paradigm shift towards more robust multiaxial catheter support systems has ushered the development of additional new intermediate support catheters similar to the Navien catheter. One such example is the Catalyst class of intermediate catheters (Stryker Neurovascular, Freemont, California, USA). The 5 French Catalyst has demonstrated significant advantages of enhanced trackability with reliable stable intracranial support for delivery of modern neuroendovascular devices, including flow diverters such as the PED Flex and Surpass, as well as the intrasaccular devices such as the WEB (senior authors' experience, unpublished data). The importance of stable catheter support systems translates to improved safety and ease for sophisticated neurointerventional treatments.

\section{PENDING NEW TECHNOLOGY}

An array of potential new technology is on the horizon for the neurointerventional field. These include coated flow diverters for reduced thrombogenicity, selfexpanding three-dimensional mesh endosaccular device called the Medina (Medtronic Neurovascular, Irvine, California, USA), smaller profile WEB devices to address broader range of aneurysm sizes (figure 5), and an additional new intrasaccular flow disrupter called the Artis device (Medtronic Neurovascular, Irvine, California, USA). These new technologies will continue to expand the neuroendovascular tools available to treat a wide variety of aneurysm types with improved safety and efficacy. It is fair to say the management of intracranial aneurysms is constantly evolving, with sophisticated technology at the forefront of innovation.

Contributors BJ drafted the manuscript. MP provided illustration of the flow diversion concept. GPC and ALC assisted in critically revising the manuscript. L-ML conceived of the manuscript and critically reviewed the important intellectual content. All authors read and approved the final manuscript.

Competing interests ALC is a proctor for the Pipeline Embolization Device (Medtronic Neurovascular, Irvine, California, USA) and a consultant for Medtronic; a proctor for the Surpass device (Stryker Neurovascular, Fremont, California, USA) and a consultant for Stryker Neurovascular; a proctor for the Flow-Redirection Endoluminal Device (FRED) device (Microvention, Tustin, California, USA) and a consultant for Microvention; a proctor for the Woven EndoBridge (WEB) device (Sequent Medical, Aliso Viejo, California, USA) and a consultant for Sequent. GPC is a consultant for Medtronic Neurovascular and Microvention.

Provenance and peer review Commissioned; externally peer reviewed.

Data sharing statement No additional data are available.

Open Access This is an Open Access article distributed in accordance with the Creative Commons Attribution Non Commercial (CC BY-NC 4.0) license, which permits others to distribute, remix, adapt, build upon this work noncommercially, and license their derivative works on different terms, provided the original work is properly cited and the use is non-commercial. See: http:// creativecommons.org/licenses/by-nc/4.0/

\section{REFERENCES}

1. Dandy WE. Intracranial aneurysm of the internal carotid artery: cured by operation. Ann Surg 1938;107:654-9.

2. Molyneux A, Kerr R, International Subarachnoid Aneurysm Trial Collaborative G, et al. International Subarachnoid Aneurysm Trial (ISAT) of neurosurgical clipping versus endovascular coiling in 2143 patients with ruptured intracranial aneurysms: a randomized trial. J Stroke Cerebrovasc Dis 2002;11:304-14.

3. Spetzler RF, McDougall CG, Zabramski JM, et al. The Barrow Ruptured Aneurysm Trial: 6-year results. J Neurosurg 2015;123:609-17.

4. Raymond J, Guilbert F, Weill A, et al. Long-term angiographic recurrences after selective endovascular treatment of aneurysms with detachable coils. Stroke 2003;34:1398-403.

5. Gory B, Turjman F. Endovascular treatment of 404 intracranial aneurysms treated with nexus detachable coils: short-term and mid-term results from a prospective, consecutive, European multicenter study. Acta Neurochir (Wien) 2014;156:831-7.

6. Brinjikji W, White PM, Nahser $\mathrm{H}$, et al. HydroCoils are associated with lower angiographic recurrence rates than are bare platinum coils in treatment of "difficult-to-treat" aneurysms: a post hoc subgroup analysis of the HELPS trial. AJNR Am J Neuroradiol 2015;36:1689-94.

7. Taschner CA, Chapot R, Costalat V, et al. GREAT-a randomized controlled trial comparing HydroSoft/HydroFrame and bare platinum coils for endovascular aneurysm treatment: procedural safety and core-lab-assessedangiographic results. Neuroradiology Published Online First: 30 Apr 2016. doi:10.1007/s00234-016-1693-y 
8. Akpek $\mathrm{S}$, Arat A, Morsi $\mathrm{H}$, et al. Self-expandable stent-assisted coiling of wide-necked intracranial aneurysms: a single-center experience. AJNR Am J Neuroradiol 2005;26:1223-31.

9. Colby GP, Paul AR, Radvany MG, et al. A single center comparison of coiling versus stent assisted coiling in 90 consecutive paraophthalmic region aneurysms. J Neurointerv Surg 2012;4:116-20

10. Piotin M, Blanc R, Spelle L, et al. Stent-assisted coiling of intracranial aneurysms: clinical and angiographic results in 216 consecutive aneurysms. Stroke 2010;41:110-15.

11. Dengler J, Maldaner N, Glasker S, et al. Outcome of surgical or endovascular treatment of giant intracranial aneurysms, with emphasis on age, aneurysm location, and unruptured aneurysms-a systematic review and meta-analysis. Cerebrovasc Dis 2016;41:187-98.

12. Hauck EF, Welch BG, White JA, et al. Stent/coil treatment of very large and giant unruptured ophthalmic and cavernous aneurysms. Surg Neurol 2009;71:19-24; discussion 24.

13. Aenis M, Stancampiano AP, Wakhloo AK, et al. Modeling of flow in a straight stented and nonstented side wall aneurysm model. J Biomech Eng 1997;119:206-12.

14. Hoi Y, Ionita CN, Tranquebar RV, et al. Flow modification in canine intracranial aneurysm model by an asymmetric stent: studies using digital subtraction angiography (DSA) and image-based computational fluid dynamics (CFD) analyses. Proc SPIE Int Soc Opt Eng 2006;6143:61430J.

15. Krishna C, Sonig A, Natarajan SK, et al. The expanding realm of endovascular neurosurgery: flow diversion for cerebral aneurysm management. Methodist Debakey Cardiovasc J 2014;10:214-19.

16. Nelson PK, Lylyk P, Szikora I, et al. The pipeline embolization device for the intracranial treatment of aneurysms trial. AJNR Am J Neuroradiol 2011;32:34-40.

17. Administration. UFaD. Pipeline embolization device PMA P100018. Summary of safety and effectiveness data. 2011. http://www. accessdata.fda.gov/cdrh_docs/pdf10/p100018b.pdf

18. Colby GP, Lin LM, Caplan JM, et al. Immediate procedural outcomes in 44 consecutive Pipeline Flex cases: the first North American single-center series. J Neurointerv Surg 2016;8:702-9.

19. Lylyk P, Miranda C, Ceratto R, et al. Curative endovascular reconstruction of cerebral aneurysms with the pipeline embolization device: the Buenos Aires experience. Neurosurgery 2009;64:632-42; discussion 42-3; quiz N6.

20. Szikora I, Berentei Z, Kulcsar Z, et al. Treatment of intracranial aneurysms by functional reconstruction of the parent artery: the Budapest experience with the pipeline embolization device. AJNR Am J Neuroradiol 2010;31:1139-47.

21. Becske T, Kallmes DF, Saatci I, et al. Pipeline for uncoilable or failed aneurysms: results from a multicenter clinical trial. Radiology 2013;267:858-68

22. Colby GP, Lin LM, Gomez JF, et al. Immediate procedural outcomes in 35 consecutive pipeline embolization cases: a single-center, single-user experience. J Neurointerv Surg 2013;5:237-46.

23. Colby GP, Lin LM, Paul AR, et al. Cost comparison of endovascular treatment of anterior circulation aneurysms with the pipeline embolization device and stent-assisted coiling. Neurosurgery 2012;71:944-8; discussion 48-50.

24. Colby GP, Lin LM, Nundkumar N, et al. Radiation dose analysis of large and giant internal carotid artery aneurysm treatment with the pipeline embolization device versus traditional coiling techniques. J Neurointerv Surg 2015;7:380-4.

25. Investigators UJ, Morita A, Kirino T, et al. The natural course of unruptured cerebral aneurysms in a Japanese cohort. $N$ Engl J Med 2012;366:2474-82.

26. Wiebers DO, Whisnant JP, Huston J III, et al. Unruptured intracranial aneurysms: natural history, clinical outcome, and risks of surgical and endovascular treatment. Lancet 2003;362:103-10.

27. Roessler K, Cejna M, Zachenhofer I. Aneurysmatic subarachnoida haemorrhage: incidence and location of small ruptured cerebral aneurysms-a retrospective population-based study. Wien Klin Wochenschr 2011;123:444-9.

28. Lin LM, Colby GP, Kim JE, et al. Immediate and follow-up results for 44 consecutive cases of small $(<10 \mathrm{~mm})$ internal carotid artery aneurysms treated with the pipeline embolization device. Surg Neurol Int 2013;4:114.

29. Chan TT, Chan KY, Pang PK, et al. Pipeline embolisation device for wide-necked internal carotid artery aneurysms in a hospital in Hong Kong: preliminary experience. Hong Kong Med $J$ 2011;17:398-404.
30. Lubicz B, Collignon L, Raphaeli G, et al. Pipeline flow-diverter stent for endovascular treatment of intracranial aneurysms: preliminary experience in 20 patients with 27 aneurysms. World Neurosurg 2011;76:114-19.

31. Albuquerque FC, Park MS, Abla AA, et al. A reappraisal of the Pipeline embolization device for the treatment of posterior circulation aneurysms. J Neurointerv Surg 2015;7:641-5.

32. Brouillard $\mathrm{AM}$, Sun $\mathrm{X}$, Siddiqui $\mathrm{AH}$, et al. The use of flow diversion for the treatment of intracranial aneurysms: expansion of indications. Cureus 2016;8:e472.

33. Chalouhi N, Zanaty M, Whiting A, et al. Safety and efficacy of the Pipeline Embolization Device in 100 small intracranial aneurysms. J Neurosurg 2015;122:1498-502.

34. Briganti F, Leone G, Marseglia M, et al. Endovascular treatment of cerebral aneurysms using flow-diverter devices: a systematic review. Neuroradiol J 2015;28:365-75.

35. Wakhloo AK, Lylyk P, de Vries J, et al. Surpass flow diverter in the treatment of intracranial aneurysms: a prospective multicenter study. AJNR Am J Neuroradiol 2015;36:98-107.

36. Colby GP, Lin LM, Caplan JM, et al. Flow diversion of large internal carotid artery aneurysms with the surpass device: impressions and technical nuance from the initial North American experience. $J$ Neurointerv Surg 2016;8:279-86.

37. Strauss I, Maimon S. Silk flow diverter in the treatment of complex intracranial aneurysms: a single-center experience with 60 patients. Acta Neurochir (Wien) 2016;158:247-54.

38. Lubicz B, Van der Elst O, Collignon L, et al. Silk flow-diverter stent for the treatment of intracranial aneurysms: a series of 58 patients with emphasis on long-term results. AJNR Am J Neuroradiol 2015;36:542-6.

39. Shankar JJ, Tampieri D, lancu D, et al. SILK flow diverter for complex intracranial aneurysms: a Canadian registry. J Neurointerv Surg 2016;8:273-8.

40. Diaz O, Gist TL, Manjarez G, et al. Treatment of 14 intracranial aneurysms with the FRED system. J Neurointerv Surg 2014;6:614-17.

41. Briganti F, Leone G, Marseglia M, et al. p64 Flow Modulation Device in the treatment of intracranial aneurysms: initial experience and technical aspects. J Neurointerv Surg 2016;8:173-80.

42. Zhou Y, Yang PF, Fang YB, et al. A novel flow-diverting device (Tubridge) for the treatment of 28 large or giant intracranial aneurysms: a single-center experience. AJNR Am J Neuroradiol 2014;35:2326-33

43. Zhou Y, Yang PF, Fang YB, et al. Parent artery reconstruction for large or giant cerebral aneurysms using a Tubridge flow diverter (PARAT): study protocol for a multicenter, randomized, controlled clinical trial. BMC Neurol 2014;14:97.

44. Pierot L, Liebig T, Sychra V, et al. Intrasaccular flow-disruption treatment of intracranial aneurysms: preliminary results of a multicenter clinical study. AJNR Am J Neuroradiol 2012;33:1232-8.

45. Mine B, Pierot L, Lubicz B. Intrasaccular flow-diversion for treatment of intracranial aneurysms: the Woven EndoBridge. Expert Rev Med Devices 2014:11:315-25.

46. Papagiannaki $C$, Spelle $L$, Januel $A C$, et al. WEB intrasaccular flow disruptor-prospective, multicenter experience in 83 patients with 85 aneurysms. AJNR Am J Neuroradiol 2014;35:2106-11.

47. Pierot L, Klisch J, Cognard C, et al. Endovascular WEB flow disruption in middle cerebral artery aneurysms: preliminary feasibility, clinical, and anatomical results in a multicenter study. Neurosurgery 2013;73:27-34; discussion 34-5.

48. Pierot L, Spelle L, Molyneux A, et al., WEBCAST and French Observatory Investigators. Clinical and anatomical follow-up in patients with aneurysms treated with the WEB device: 1-year follow-up report in the cumulated population of 2 prospective, multicenter series (WEBCAST and French Observatory). Neurosurgery 2016;78:133-41.

49. Colby GP, Lin LM, Huang J, et al. Utilization of the Navien distal intracranial catheter in 78 cases of anterior circulation aneurysm treatment with the Pipeline embolization device. J Neurointerv Surg 2013;5(Suppl 3):iii16-21.

50. Lin LM, Colby GP, Huang J, et al. Ultra-distal large-bore intracranial access using the hyperflexible Navien distal intracranial catheter for the treatment of cerebrovascular pathologies: a technical note. $J$ Neurointerv Surg 2014;6:301-7.

51. Lin LM, Colby GP, Jiang B, et al. Intra-DIC (distal intracranial catheter) deployment of the Pipeline embolization device: a nove rescue strategy for failed device expansion. J Neurointerv Surg 2016;8:840-6. 